\title{
Determination of Epicenters before Earthquakes Utilizing Far Seismic and GNSS Data: Insights from Ground Vibrations
}

\author{
Chieh-Hung Chen ${ }^{1,2}, * \mathbb{D}$, Li-Ching Lin ${ }^{3}$, Ta-Kang Yeh ${ }^{4} \oplus$, Strong Wen ${ }^{5}$, Huaizhong Yu ${ }^{6}$, \\ Chen Yu ${ }^{6}$, Yongxin Gao ${ }^{7}$, Peng Han ${ }^{8}{ }^{10}$, Yang-Yi Sun ${ }^{2}$, Jann-Yenq Liu 9, 10,11, Cheng-Horng Lin ${ }^{12}$, \\ Chi-Chia Tang ${ }^{2}$, Che-Min Lin ${ }^{13}\left(\mathbb{D}\right.$, Hung-Hao Hsieh ${ }^{13}$ and Pin-Ji Lu ${ }^{14}$ \\ 1 State Key Laboratory of Geological Processes and Mineral Resources, China University of Geosciences, \\ Wuhan 430074, China \\ 2 Institute of Geophysics and Geomatics, China University of Geosciences, Wuhan 430074, China; \\ sunyy@cug.edu.cn (Y.-Y.S.); cctang@cug.edu.cn (C.-C.T.) \\ 3 National Applied Research Laboratories, Taipei 10636, Taiwan; plih@narlabs.org.tw \\ 4 Department of Real Estate and Built Environment, National Taipei University, New Taipei 23741, Taiwan; \\ bigsteel@mail.ntpu.edu.tw \\ 5 Department of Earth and Environmental Sciences, National Chung Cheng University, Chia-Yi 62102, Taiwan; \\ strong@eq.ccu.edu.tw \\ 6 China Earthquake Networks Center, Beijing 100045, China; yuhz@seis.ac.cn (H.Y.); yuchen@seis.ac.cn (C.Y.) \\ 7 School of Civil Engineering, Hefei University of Technology, Hefei 230009, China; gaoyx@hfut.edu.cn \\ 8 Department of Earth and Space Sciences, Southern University of Science and Technology, \\ Shenzhen 518055, China; hanp@sustech.edu.cn \\ 9 Graduate Institute of Space Science, National Central University, Taoyuan 32001, Taiwan; \\ jyliu@jupiter.ss.ncu.edu.tw \\ 10 Center for Space and Remote Sensing Research, National Central University, Taoyuan 32001, Taiwan \\ 11 Center for Astronautical Physics and Engineering, National Central University, Taoyuan 32001, Taiwan \\ 12 Institute of Earth Sciences, Academia Sinica, Taipei 11529, Taiwan; lin@earth.sinica.edu.tw \\ 13 National Center for Research on Earthquake Engineering, Taipei 106219, Taiwan; \\ cmlin@narlabs.org.tw (C.-M.L.); hhhsieh@narlabs.org.tw (H.-H.H.) \\ 14 Key Laboratory of Earthquake Geodesy, Institute of Seismology, China Earthquake Administration, \\ Wuhan 430071, China; pinjilv@eqhb.gov.cn \\ * Correspondence: zjq02010@cug.edu.cn; Tel.: +86-177-7183-9292
}

Received: 10 June 2020; Accepted: 5 October 2020; Published: 7 October 2020

\begin{abstract}
Broadband seismometers, ground-based Global Navigation Satellite Systems (GNSS), and magnetometers that were located within an epicentral distance of approximately $150 \mathrm{~km}$ consistently observed the novel anomalous behaviors of the common-mode ground vibrations approximately 5-10 days before the M6.6 Meinong earthquake in Taiwan. The common-mode ground vibrations with amplitudes near $0.1 \mathrm{~m}$ at frequencies ranging from $8 \times 10^{-5}$ to $2 \times 10^{-4} \mathrm{~Hz}$ were generated near the region close to the epicenter of the impending earthquake. The common-mode vibrations were consistently observed in seismic and GNSS data associated with five other earthquakes in four distinct areas. The results reveal that the common-mode vibrations could be a typical behavior before earthquakes. The causal mechanism of common-mode vibrations can be attributed to crustal resonance excitations before fault dislocations occur. Potential relationships with other pre-earthquake anomalies suggest that the common-mode vibrations could be ground motion before earthquakes, which was investigated for a significant length of time.
\end{abstract}

Keywords: common-mode ground vibrations; pre-earthquake ground motion; pre-earthquake anomalous phenomena 


\section{Introduction}

The existence of pre-earthquake anomalous phenomena is a highly controversial issue in the scientific community [1-4]. This debate exists mainly because these phenomena generally pass statistical tests, but they originate from unknown sources [5-7]. Atmospheric acoustic-gravity waves have been considered as one of the factors that induce changes in ionospheric density, which could cause seismo-ionospheric perturbations before earthquakes [8-12]. However, seeking seismic-related vibration sources such as crustal displacements [13-18] and ground motion occurring before earthquakes has remained a great challenge until the present. On 6 February 2016, the M6.6 Meinong earthquake $\left(22.92^{\circ} \mathrm{N}, 120.54^{\circ} \mathrm{E}\right)$ occurred in southern Taiwan (Figure 1a), causing the loss of hundreds of lives [19]. The continuous seismic data recorded by the broadband seismometer at the $\mathrm{B} 770\left(22.54^{\circ} \mathrm{N}, 120.39^{\circ} \mathrm{E}\right)$ station, which is operated by National Center for Research on Earthquake Engineering (NCREE) of Taiwan, show that variations in the amplitude of ground velocity doubled from the background noise level (i.e., the double-amplitude vibrations) for 10-15 days before the earthquake (Figure 1b). Spectra of the double-amplitude vibrations were mainly distributed at frequencies near $1.4 \times 10^{-4} \mathrm{~Hz}$ (a period of $2 \mathrm{~h}$ ) (Figure 1c). These amplifications lasted for 10 days and became minimal within a few days after the earthquake's occurrence (Figure S1). We chose the seismic data recorded approximately 100 days before the earthquake for examining whether the existence of the amplification is permanent or provisional. Figure 1c shows that the associated amplification cannot be observed approximately 100 days before the earthquake. The result suggests that the amplifications are not permanent but could be pre-earthquake anomalous phenomena associated with the Meinong earthquake. Note that the behavior of the associated amplification at frequencies near $1.4 \times 10^{-4} \mathrm{~Hz}$ is distinct from that of slow earthquakes, microcracks, and tremors, which are observed at relatively high frequencies (0.1-10 Hz) [19-22].
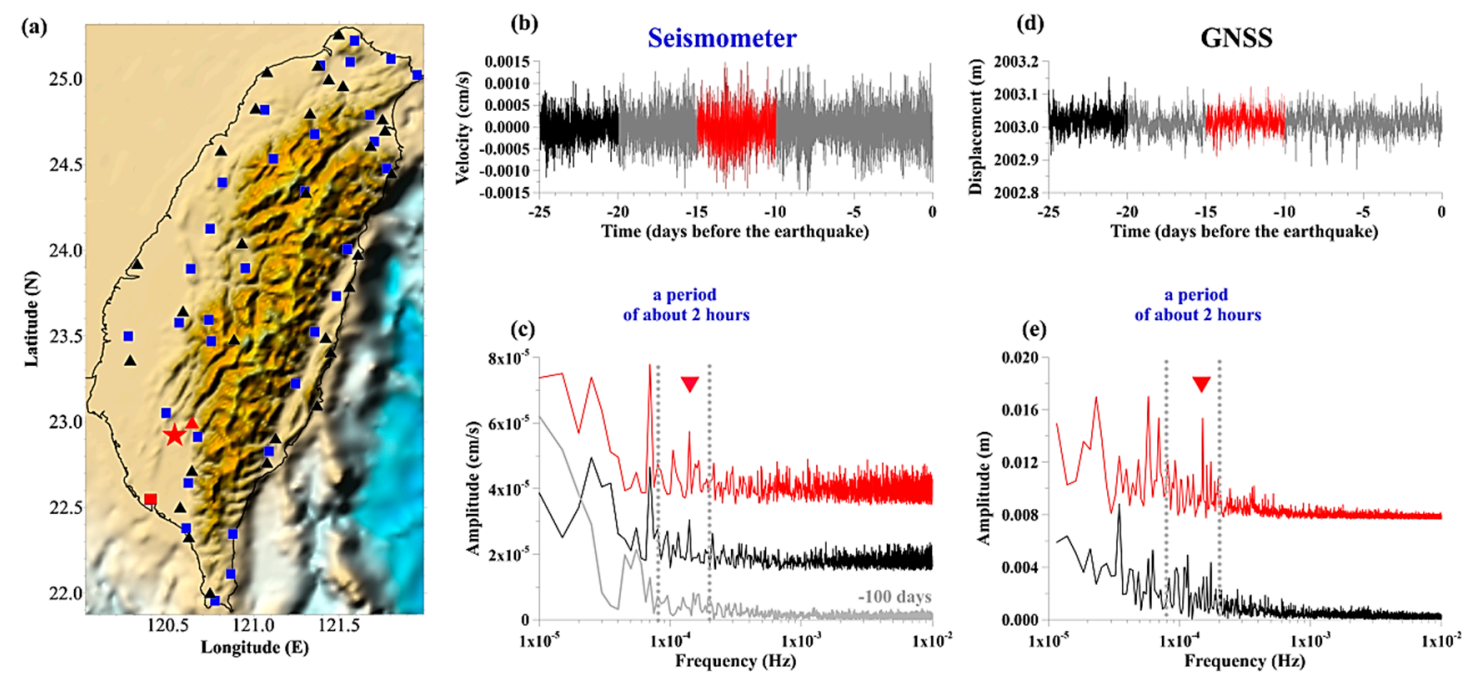

Figure 1. Locations of seismometers and ground-based Global Navigation Satellite Systems (GNSS) receivers on a topographic map and the variations of the vertical component data from two example stations for an interval of 0-25 days before the 2016 Meinong earthquake in Taiwan. Locations of seismometers and GNSS receivers are denoted by squares and triangles, respectively, in (a). The red star shows the epicenter. Seismic and GNSS data recorded by the B770 and LGUE stations are denoted by red symbols in $(\mathbf{a})$ and are shown in $(\mathbf{b}, \mathbf{c})$ and $(\mathbf{d}, \mathbf{e})$, respectively. Note that the stations are selected based on the short epicentral distance and the continuity of the recorded data. (b) and (d) demonstrate changes in vertical velocity recorded by the seismic stations and vertical displacements recorded by the GNSS stations via the CSRS-PPP during an interval of 0-25 days before the earthquake, respectively. The amplitude varied with the frequency computed from the seismic and GNSS data in the interval of 20-25 days before the earthquake (black lines) and in the interval of 10-15 days (red lines) before 
the earthquake are shown in (c) and (e), respectively. Notably, the gray line shows the variations of amplitude retrieved from the seismic data 100 days in (c) for reference. Significant amplification of the amplitude can be found at frequencies of about $1.4 \times 10^{-4} \mathrm{~Hz}$ (a period of approximately $2 \mathrm{~h}$ ) between grey dashed lines shown with the red reversed triangles. Vertical dashed lines indicate the frequency at $8 \times 10^{-5} \mathrm{~Hz}$ (a period of $3.5 \mathrm{~h}$ ) and $2 \times 10^{-4} \mathrm{~Hz}$ (a period of $1.5 \mathrm{~h}$ ).

Surface displacements monitored by using the ground-based Global Navigation Satellite Systems (GNSS) data can exhibit similar elastic deformation and/or oscillation in the spatiotemporal domain if the double-amplitude vibrations actually exist. Vertical displacements retrieved from ground-based GNSS receivers were taken into consideration to examine whether the double-amplitude vibrations in seismic records are affected by dynamic ranges at such low frequencies (i.e., a cycle of near $2 \mathrm{~h}$ ). The GNSS data in Taiwan were provided by the Geophysical Database Management System of the Central Weather Bureau [23]. However, parts of the stations only record the Global Positioning System (GPS) observations. For the consistency of the data processing, only GPS observations were taken into account in this study. A total of thirty-six GNSS stations were selected, and the Canadian Spatial Reference System (CSRS) Precise Point Positioning (PPP) online computation system was utilized to calculate the 3D coordinates of the GNSS stations. The CSRS-PPP system uses the precise GNSS satellite orbit ephemerides; therefore, the coordinates in this study were taken from the International Terrestrial Reference Frame 2014. Moreover, the kinematic mode was adopted in the data processing and the coordinates were produced every $30 \mathrm{~s}$. To increase the accuracy of the data processing, an ocean tide loading correction was applied and the NAO.99b model was used to obtain the optimal correction effect [24]. The amplification can also be found in the vertical component of the GNSS data at the LGUE $\left(22.99^{\circ} \mathrm{N}, 120.54^{\circ} \mathrm{E}\right)$ station between 10 days and 15 days before the earthquake (Figure 1d,e). The amplification exhibits that the Earth's surface oscillates vertically with an amplitude of approximately $0.1 \mathrm{~m}$ with a cycle period of approximately $2 \mathrm{~h}$. The oscillation shares similar characteristics in the frequency (i.e., near $1.4 \times 10^{-4} \mathrm{~Hz}$ ) and the occurring time with those signals in the seismic velocity data (Figure $1 \mathrm{~d}, \mathrm{e}$ ). Meanwhile, an average rate close to $6.17 \times 10^{-6} \mathrm{~m} / \mathrm{s}$ derived from the associated oscillation of the Earth's surface also shows an agreement with the seismic data. Note that the frequency of the amplification is different compared with the well-known frequency-dependent effects (such as the lunar elliptic tides, lunar semi-diurnal tides, lunar-solar semi-diurnal tides and so on) on the surface displacements $[25,26]$.

\section{Methodology}

To understand the spatiotemporal distribution of the double-amplitude vibrations associated with the earthquake, we collected seismic ground velocity data at the thirty-one stations, which are operated by NCREE, and the GNSS data in Taiwan. The background amplitude was computed by utilizing the data in the frequency band of interest (i.e., from $8 \times 10^{-5}$ to $2 \times 10^{-4} \mathrm{~Hz}$ ) within a time span of 0-60 days before the earthquake for each station using the Fourier transform. In contrast, the monitoring amplitude was computed by using the data in the same frequency band within a moving window spanning 5 days from 25 to 0 days before the earthquake. The amplification ratio was calculated by dividing the monitoring amplitude by the background amplitude. Spatial distributions of the amplification ratios were obtained by applying a gridding method for the amplification ratios of all the stations.

Furthermore, we utilized the data at two horizontal components in each station to evaluate the azimuth of wave propagation (excited by the ground vibrations) using the maximum horizontal amplitude [27] for further determining location sources of the ground vibrations. Areas that potentially reveal the locations of sources were defined by using a sector centered on the propagation azimuth with an expansion angle of $15^{\circ}$ on both sides. This implies a resolution of $30^{\circ}$ in the determination of the propagation azimuth. The radius of a sector was determined to be $300 \mathrm{~km}$ because enhancements of $10-20 \%$ were distributed in areas covering the whole Taiwan island. The locations of sources were 
determined by using intersectional areas of the sectors, which overlapped at least three stations with significant enhancements.

On the other hand, once the multiple stations detected the double-amplitude vibrations, the principal component analysis (PCA) method [28] was also employed to extract common-mode ground vibrations from the thirty-one seismic stations in Taiwan during the Meinong earthquake. The ground velocity data within a time span of one year from all the seismic stations were filtered by using a bandpass filter of $8 \times 10^{-5}-2 \times 10^{-4} \mathrm{~Hz}$ (i.e., a period of $1.5-3.5 \mathrm{~h}$ ). Strong peak values, which are caused by unwanted influences (i.e., artificial noise, local earthquakes, teleseismic waves and so on), were mitigated through the summation of the filtered amplitudes as a daily value [29]. The summated daily values at all the stations were processed through the PCA method, to extract common-mode ground vibrations during the Meinong earthquake. The PCA method is a statistical procedure that widely utilizes an orthogonal transformation to convert a set of observations of possibly correlated variables into a set of linearly uncorrelated variables called principal components [28]. The first principal component retrieved from the PCA method was determined as the common-mode ground vibrations that were further compared with other potential interferences to clarify the causal mechanism. Finally, Molchan's error diagram [30] was utilized to evaluate the prediction performance of the phenomena of the common-mode ground vibrations for earthquake forecasting. Molchan's error diagram can evaluate the prediction curve via the rate of earthquakes detected against the rate of alarming cells. Notably, a modified area skill score measured the area between the actual prediction curve and the random prediction line that is conducted in Molchan's error diagram. The scores above zero indicated that the prediction is better than the random and the observation contained precursory information. We show the flow chart in Figure 2.

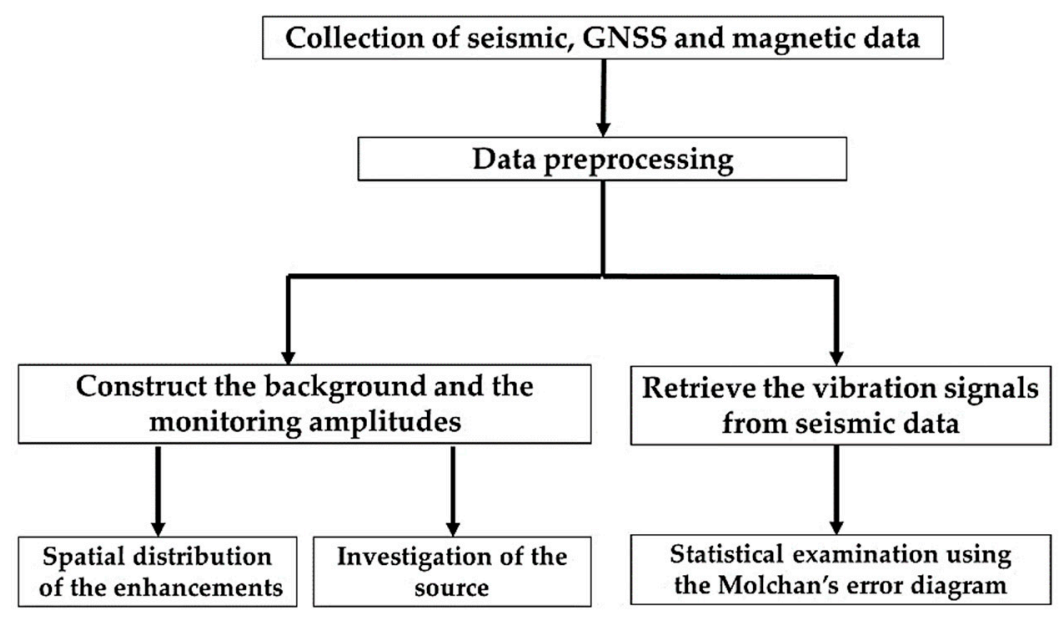

Figure 2. The flow chart of this study.

\section{The Spatiotemporal Distribution and the Source Location of the Vibrations}

The amplification ratio of the vertical seismic data was near one for 10 days before the earthquake (Figure $3 \mathrm{a}-\mathrm{c}$ ). In contrast, the amplification ratio significantly enhanced to close to 2 and was widely distributed in the area entirely covering Taiwan about 5-10 days before the earthquake (Figure $3 \mathrm{~d}$ ). In terms of $0-5$ days before the earthquake, the enhancements gradually attenuated in the whole study area, except for a local region in the southern part of Taiwan (Figure 3e). Regarding the amplification ratio of the vertical displacement of the GNSS data, the ratios were roughly near 1 for approximately 10-25 days before the earthquake (Figure 3f-h). The ratios obviously enhanced to 2 about 10 days before the earthquake that roughly covered the whole Taiwan island (Figure 3i). Similarly, the ratios attenuated to about 1 and were comparable with the background (i.e., 10-25 days before the earthquake) for $0-5$ days before the earthquake. In short, consistent behaviors related to the changes in time-variant spatial distributions can be seen in the GNSS data (Figure 3f-j). The amplification ratio near 2 distributes 
in a wide area that is significantly larger than the fault rupture zone of the earthquake about 5-10 days before the event. However, the boundary of the enhancements is vague due to the limitation posed by the land area of Taiwan.
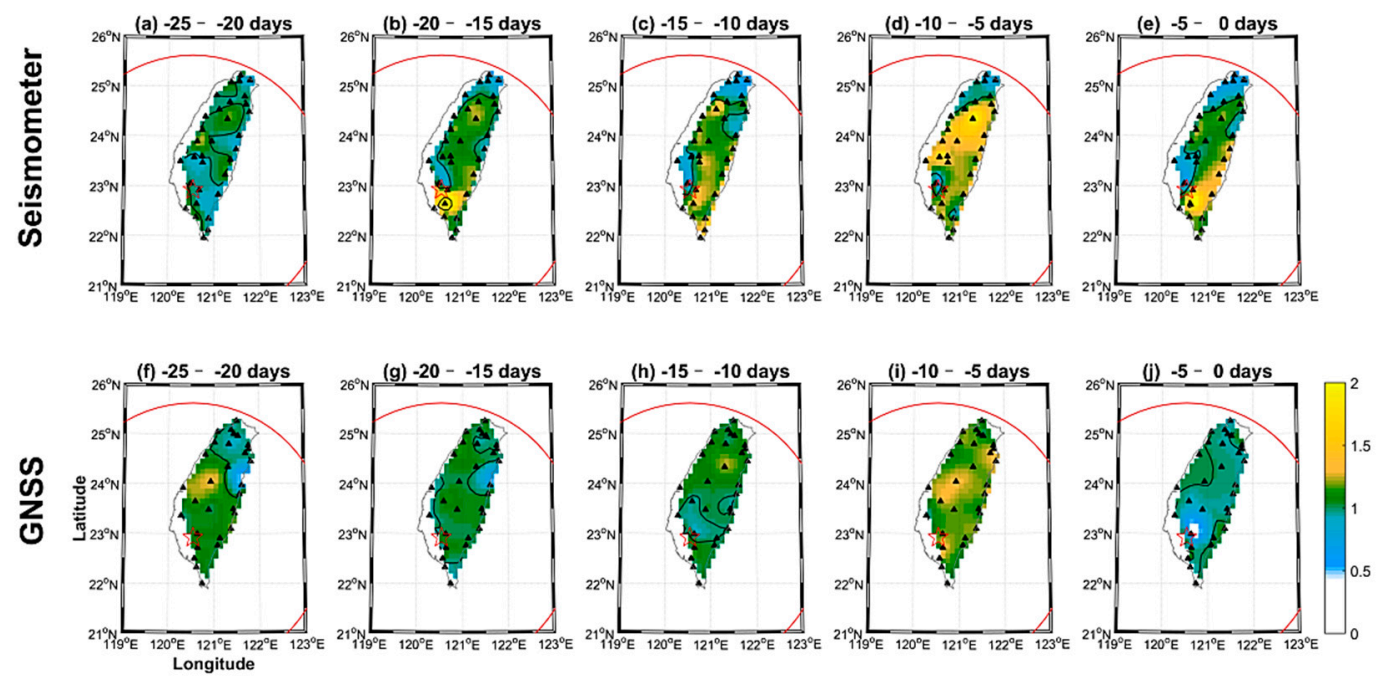

Figure 3. Spatial distribution of amplification ratios computed from data for an interval of 0-25 days before the Meinong earthquake. The upper $(\mathbf{a}-\mathbf{e})$ and lower $(\mathbf{f}-\mathbf{j})$ panels denote amplification ratios obtained from seismic and GNSS data. The amplification ratio of $>1$ (or $<1$ ) suggests enhancement (or attenuation) of ground vibrations in the particular duration. Time intervals of 5 days were used for the analysis process. The red star denotes the epicenter. Red curves indicate portions of circles with a radius of $300 \mathrm{~km}$ from the epicenter of the earthquake.

In Figure 4, we further discuss the source location of the enhancements associated with the ground vibrations. No obvious source location can be observed 15 days before the earthquake from either seismic (Figure $4 \mathrm{a}-\mathrm{c}$ ) or GNSS (Figure $4 \mathrm{f}-\mathrm{h}$ ) data due to insignificant enhancements (Figure 3a-c and $\mathrm{f}-\mathrm{h}$ ). In contrast, seismic and GNSS data indicate the coincidence of the intersectional areas located close to the epicenter of the Meinong earthquake that can be observed about 5-10 days before the event (Figure $4 \mathrm{~d}, \mathrm{i}$ ). In terms of $0-5$ days before the earthquake, no source location can be determined (Figure $4 \mathrm{e}, \mathrm{j}$ ) due to the attenuation of the enhancements.
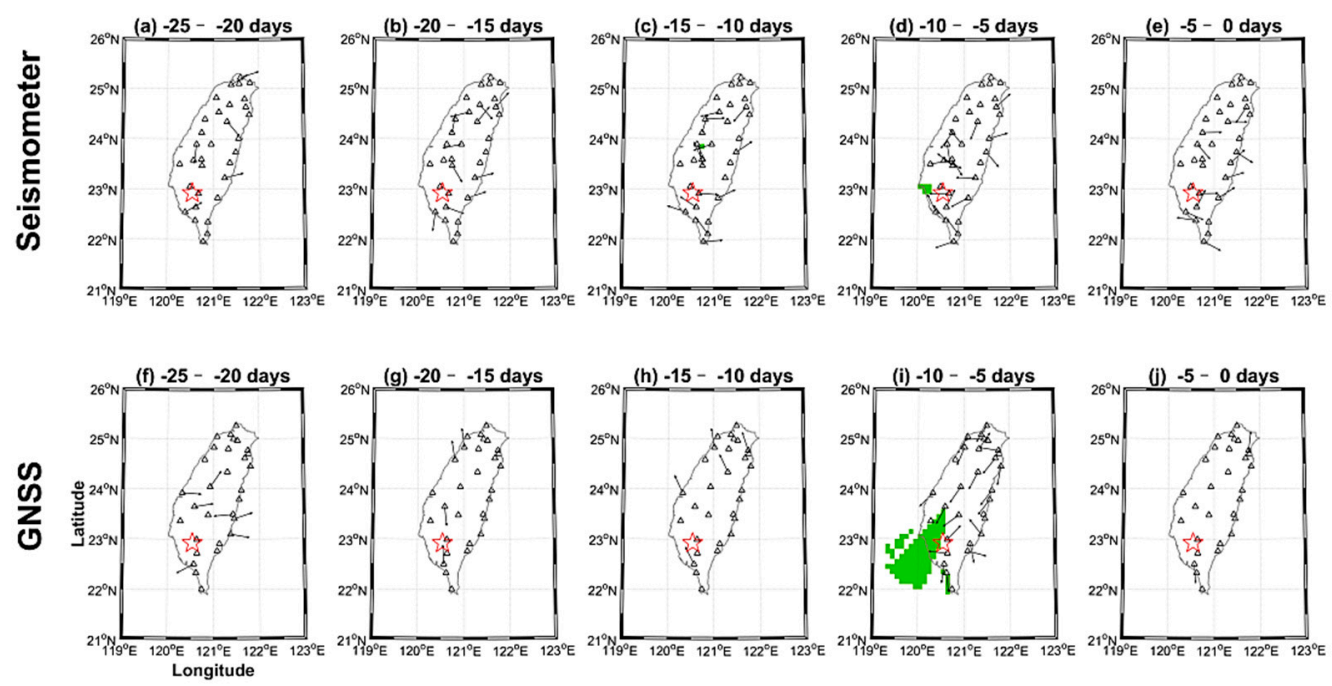

Figure 4. Locations of the vibration sources determined using seismic and GNSS data for an interval of 0-25 days before the Meinong earthquake. The upper and lower panels show locations obtained from 
seismic and GNSS data, respectively, in distinct time spans following (a-j). Black arrows lie on stations with significant amplitude enhancements, as shown in Figure 3, and point toward potential sources of crustal vibration excitation before the earthquake. The red star denotes the epicenter. Green areas on the map indicate the locations of potential crustal vibration sources, as determined by at least three stations showing significant enhancement.

\section{The Principal Component Analysis and the Molchan's Error Diagrams}

Figure 3d,i show the distribution of the enhancements in a wide area that suggests the existence of common-mode vibrations before the earthquake. Vertical velocity data at all the seismic stations from 200 days before to 150 days after the Meinong earthquake were filtered by using the band-pass filter of $8 \times 10^{-5}-2 \times 10^{-4} \mathrm{~Hz}$ to examine the similarity of the time-varied amplitude in different stations along the time. The results show that the amplitude of filtered data exhibits similar changes in wave envelopes among the most stations along the time (Figure 5). The applied PCA method can retrieve a common component of data recorded from multiple stations regardless of the spatial distribution due to the fact that the enhancements cover the whole Taiwan island.

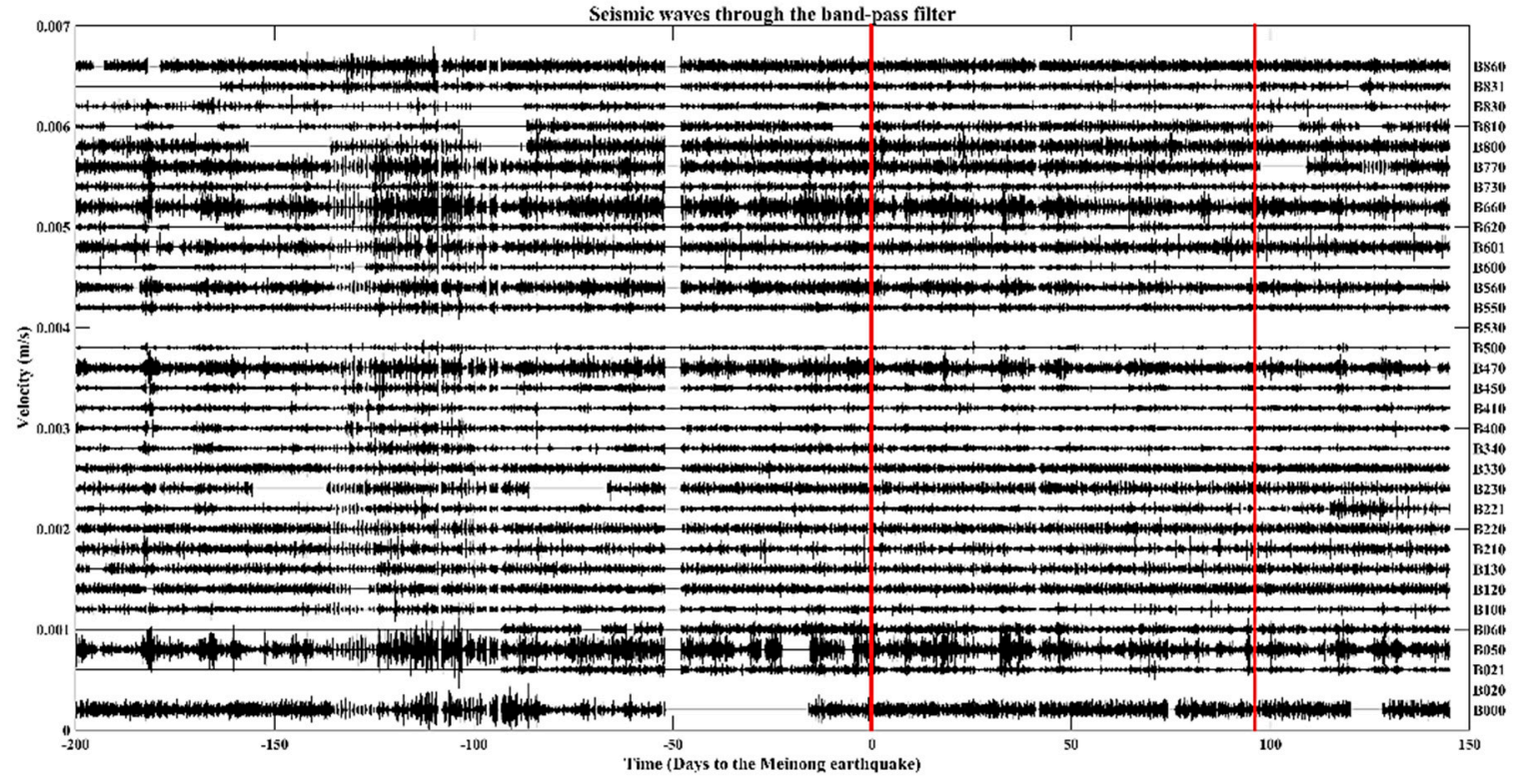

Figure 5. Variations of seismic velocity data in the vertical component filtered using a bandpass filter of $8 \times 10^{-5}-2 \times 10^{-4} \mathrm{~Hz}$ from 200 days before to 150 days after the Meinong earthquake. Red lines indicate occurrence times of two $M>6$ earthquakes listed in Table 1. Similar variations can be seen from most stations in Taiwan. Notably, gaps were found in data from the B020 and B530 stations and are ignored in this study.

Table 1. Table1. Earthquake information in Taiwan from 200 days before and 150 days after the Meinong earthquake. Earthquakes with magnitude $>6.0$ are listed.

\begin{tabular}{cccccccc}
\hline Year & Month & Day & Magnitude & Longitude $\left({ }^{\circ}\right.$ E) & Latitude $\left({ }^{\circ} \mathbf{N}\right)$ & Depth $(\mathbf{k m})$ & Days to the EQ \\
\hline 16 & 2 & 5 & 6.6 & 120.544 & 22.922 & 14.6 & 0 \\
16 & 5 & 12 & 6.1 & 121.980 & 24.692 & 8.9 & 96 \\
\hline
\end{tabular}

The analytical results show that the first principal component with the enhancements appeared approximately 20 days before the Meinong earthquake (Figure 6a). The principal component retrieved from stations located within the area with a radius $>100 \mathrm{~km}$ suggeststhe common-mode vibrations and local events (such as artificial activity, landslides, etc.) are not driving sources. Severe weather (e.g., typhoons) can also enhance ground vibrations in this frequency band for a short duration (Figure 6a). Typhoons impacted the Taiwan area at both ends of the studied one-year interval. Time 
discrepancies reveal that the common mode is not dominated by severe weather. Additionally, foreshocks (with an epicentral distance $<50 \mathrm{~km}$ ) maintain at a low level (i.e., approximately 25 events per day). They are not the primary factor triggering the common-mode vibrations.
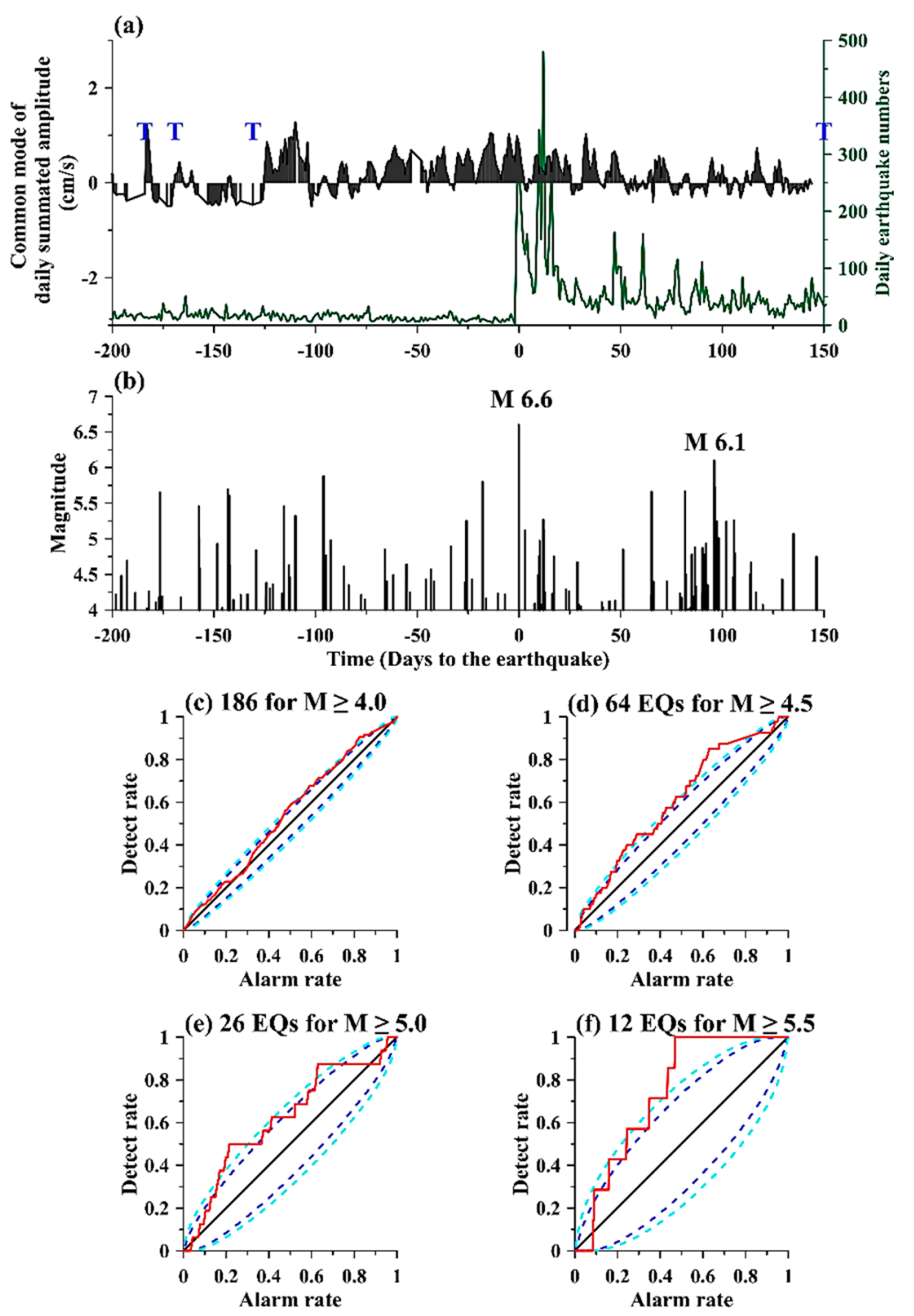

Figure 6. The common mode of daily summated amplitude from 200 days before to 150 days after the Meinong earthquake. The common-mode vibrations are determined by using the first principal components retrieved from the PCA method shown in (a). The green line reveals the daily count of earthquakes in the Taiwan areas. T marks (in blue) indicate the time that typhoons impacted Taiwan. Occurrence times of earthquakes with magnitude $\geq 4$ during the study period are shown in (b). Two major earthquakes with magnitude $\geq 6.0$ are marked. The associated information is shown in Table 1. (c-f) demonstrate Molchan's error diagrams of the optimal prediction strategy based on the first principal component versus to earthquakes with different criteria of their magnitude. The prediction curve shown by the red line is clearly above the random prediction line given by the black diagonal line. The $90 \%$ and $95 \%$ confidence intervals are shown by the dashed dark blue and dashed blue lines, respectively.

To examine whether the common-mode ground vibrations can be rerated as a useful precursory information in Taiwan, Molchan's error diagram is utilized to assess the efficiency of prediction strategies for different earthquake magnitudes. We used 186 earthquakes with magnitude $\geq 4$ that 
recorded by the Central Weather Bureau, Taiwan, and occurred around the Taiwan area during the study period (Figure 6b) to examine whether the common-mode vibrations contain precursory information statistically. The statistical results show that the prediction curve and the $90 \%$ confidence interval are comparable for earthquakes with magnitude $\geq 4$ and $\geq 4.5$ (Figure $6 c$,d). In contrast, most of the prediction curve is over the $90 \%$ confidence interval, and quite a lot exceeds the $95 \%$ confidence interval that can be found for earthquakes with magnitude $\geq 5.0$ and $\geq 5.5$ (Figure 6e,f). These results suggest that the common-mode ground vibrations are highly related to earthquakes with magnitude $\geq$ 5. In other words, the common-mode ground vibrations are difficult to distinguish from the noise for earthquakes with magnitude $<5$.

\section{Discussions and Conclusions}

Can the common-mode ground vibrations be observed in other events or in distinct areas in the world? Here, we take the seismic and GNSS data associated with the other five earthquakes with magnitudes of 6-7 (Table 2) from world data centers (also see the supplementary) for further examining whether the phenomena of the common-mode vibrations have typical characteristics (Figures S2-S16). The selection of the earthquakes is done according to the available data and the existence of adequate observational networks. The amplification in the relevant frequency band tends to be high around 0-10 days before the earthquake. This can be consistently found in both the seismic and GNSS data before the earthquakes, except for the largest M7.2 Baja earthquake. The Baja earthquake has the amplifications in a wide frequency band from $6 \times 10^{-5}$ to $2 \times 10^{-4} \mathrm{~Hz}$ (i.e., a period of 1.5-4.5 h) appearing $0-5$ days before. The significant amplification can be consistently observed from the seismic or GNSS stations near the epicenters. The $10-20 \%$ enhancements of the amplification ratios are roughly distributed in the areas with epicentral distances of less than $300 \mathrm{~km}$. The intersectional areas determined from the stations with the enhancements are located close to the epicenters. This suggests that the common-mode vibrations probably relate to these selected earthquakes.

Table 2. Occurrence time and locations of the six selected earthquakes utilized in this study.

\begin{tabular}{cccc}
\hline Earthquake & Date & Location & Country or Areas \\
\hline M6 Parkfield EQ & 28 September 2004 & $35.8^{\circ} \mathrm{N}, 120.4^{\circ} \mathrm{W}$ & United States \\
M7.2 Baja EQ & 4 April 2010 & $38.2^{\circ} \mathrm{N}, 122.3^{\circ} \mathrm{W}$ & Mexico \\
M6.6 Jinggu EQ & 7 October 2014 & $23.4^{\circ} \mathrm{N}, 100.5^{\circ} \mathrm{E}$ & China \\
M6.5 Ludian EQ & 3 August 2014 & $27.1^{\circ} \mathrm{N}, 103.3^{\circ} \mathrm{E}$ & China \\
M6.6 Meinong EQ & 6 February 2016 & $22.9^{\circ} \mathrm{N}, 120.5^{\circ} \mathrm{E}$ & Taiwan \\
M6.0 Hualien EQ & 6 February 2018 & $24.1^{\circ} \mathrm{N}, 121.7^{\circ} \mathrm{E}$ & Taiwan \\
\hline
\end{tabular}

Based on the amplifications in Figure 2, and the common-mode ground vibrations obtained from the seismic stations in Figure 5, the seismo-ground vibrations are distributed in a wide area before earthquakes can be concluded. The distribution covers a vast area that is obviously different from the common idea that earthquake-related stress accumulates within fault zones, triggering dislocation. Previous studies [31] proposed that pre-earthquake anomalous phenomena can be distributed in a wide area (called earthquake preparation zones) through the numerical method. Chen et al. [14] examined the GNSS data in Taiwan and found the filtered crustal displacements that can be dominated by far larger earthquakes (with a distance of more than $200 \mathrm{~km}$ ) before they occur. Chen et al. [32] utilized the same method proposed in [14] to examine the filtered displacements before the 2011 M9 Tohoku earthquake in Japan and found that the crustal displacements in areas with an epicentral distance $>1500 \mathrm{~km}$ are related to the event. Note that the similar anomalous phenomena of the crustal displacements associated with earthquakes can also be obtained by using the traditional method in a distinct place [13]. Chen et al. [16] utilized a statistical method to examine the relationship between seismo-crustal displacements in wide areas and earthquakes. The statistical results show 
that the relationship is more significant than random. These results roughly support the existence of common-mode ground vibrations in wide areas in this study.

If the common-mode ground vibrations in wide areas before earthquakes are true, the question remains regarding the causal mechanism that can generate relatively low frequency motion. We propose a bold hypothesis based on limited matches with physical clues observed in this study. Crustal resonance is a potential causal mechanism, which can excite the common-mode vibrations, when earthquake faults tend to dislocate in the lithosphere. Notably, enhancements of the vibration processes in response to dynamic loading from rock pressure experiments conducted in the laboratory have been mentioned in preliminary reports [33]. The accepted knowledge is that there is a proportional relationship between earthquake magnitude and earthquake-related stressed areas. The Baja earthquake, exhibiting the largest magnitude of 7.2 in this study, suggests that the relatively low resonant frequency was produced from a relatively large stressed volume. This agrees with the observations (intense peaks with a cycle close to $3.5 \mathrm{~h}$-see also Figure S5). We boldly raise our hypothesis that earthquake-related stress loading of a square sheet placed horizontally at the depth of the hypocenter excites crustal resonance close to breaking, not considering the fault type. The resonant frequency at $8 \times 10^{-5}-2$ $\times 10^{-4} \mathrm{~Hz}$ corresponds to a square sheet with a width ranging from 150 to $300 \mathrm{~km}$ and a thickness from 500 to $1000 \mathrm{~m}$ (Figure 7) [34,35]. Numerical simulation and observations show an agreement within an order of magnitude. These reveal that the earthquake-stressed volumes are much larger than the fault rupture zone.

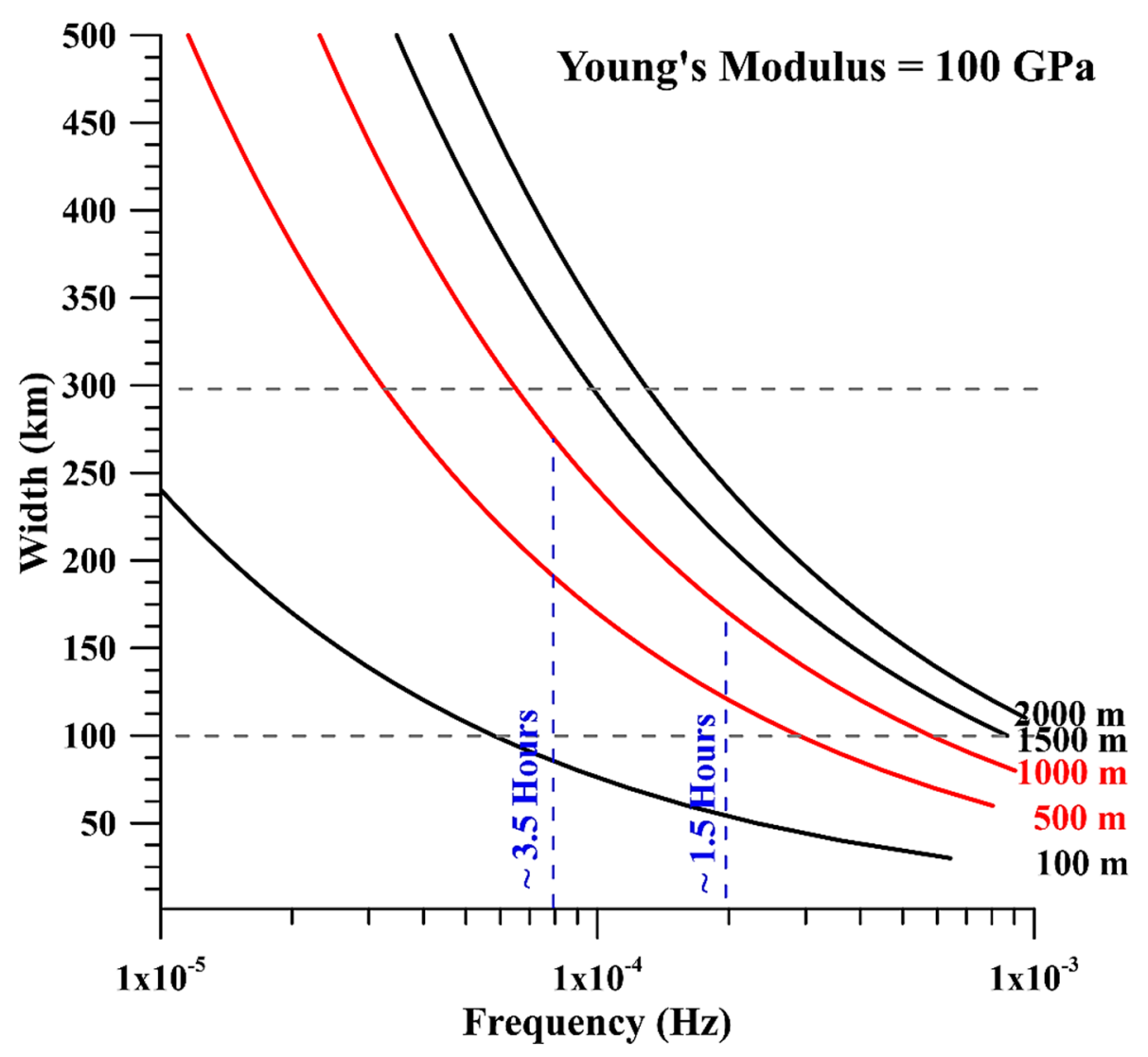

Figure 7. Relationships between the width and thickness of a square sheet and its resonant frequency. We assume that the shaking area is a square sheet with all sides simply supported. According to Leissa [33], the resonant frequency of such a square sheet can be estimated using the formula $f=\frac{1}{2 \pi} \sqrt{\frac{E h^{2}}{12\left(1-v^{2}\right) \rho}}\left[\left(\frac{m \pi}{a}\right)^{2}+\left(\frac{n \pi}{b}\right)^{2}\right]$, where $E$ is Young's modulus, $h$ is the thickness of the sheet, $\rho$ is 
the mass density, $v$ is Poisson's ratio, a and $\mathrm{b}$ are the widths of the plate, and $\mathrm{m}$ and $\mathrm{n}$ are integers. In this study, $a$ equals $b$ as the sheet is square. Young's modulus and average density of the crust are 100 $\mathrm{GPa}$ and $2700 \mathrm{~kg} / \mathrm{m}^{3}$, respectively. Poisson's ratio is 0.3 . Red and black lines indicate the relationships between the width and resonance frequency computed at varying thicknesses. Notably, $m$ and $n$ are taken as 1 to estimate the relationship based on a fundamental mode.

The common-mode vibrations can be potential sources of other pre-earthquake anomalous phenomena. Geomagnetic data show the amplification in the particular frequency band $(1.5-3.5 \mathrm{~h}$ periods) for 5-15 days before the Meinong and Parkfield earthquakes (Figures S17-S19). This generally agrees with the observations of the amplification from seismic and GNSS data, as shown in this study (Figure 1, Figure 3, Figure 4 and Figures S2-S4). Numerous earlier studies reported that the seismo-ionospheric anomalies distributed within hundreds of square kilometers over earthquake epicenters [36] are dominated by an unclear source. Widely observed common-mode vibrations are a likely candidate for possible sources, which drive large scale seismo-ionospheric anomalies. Previous studies [8-12] reported that acoustic-gravity waves can propagate upward into the ionosphere. If the common-mode vibrations are sources of the acoustic-gravity waves before earthquakes, many significant characteristics can be examined. For example, the frequency of the common-mode vibrations should be variable and tend to be high with the approaching of forthcoming earthquakes, because the acoustic-gravity waves are generally triggered by ground motion in a relatively high-frequency band [37]. This suggests that areas which trigger the common-mode vibrations change from wide to narrow based on the hypothesis of crustal resonance. Meanwhile, the acoustic-gravity waves cannot be excited by all kinds of ground vibrations, except for the pressure-shear vertical (P-SV) type motion [37]. Thus, the existence of the P-SV type motion before earthquakes can be further investigated. Once the acoustic-gravity waves are generated by the common-mode vibrations, upward propagation of the waves can change air pressure above the Earth's surface accordingly. The upward propagation of the waves can further be monitored by the magnetometers when they arrive at the altitude of about $100 \mathrm{~km}$ [37]. The total electron content (TEC) from the global dense ground-based GNSS networks, which are often used to monitor co-seismic waves in the atmosphere, can be utilized to record the waves as they reach the ionosphere. These aforementioned clues can help us to examine whether the large-scale seismo-ionospheric anomalies are driven by the widely observed common-mode vibrations.

In short, common-mode vibrations will extend the debate regarding pre-earthquake anomalous phenomena. However, examinations of potential links between pre-earthquake crustal common behavior and anomalies will guide us to the truth. While those relationships cannot be quickly proven, common-mode vibrations assist our understanding of essential duration changes taking place very close in time to earthquake occurrences.

Supplementary Materials: The following are available online at http://www.mdpi.com/2072-4292/12/19/3252/s1, The methodology and data availability for the analysis in the ground vibrations during the 2004 Parkfield, 2010 Baja, 2014 Jinggu, 2014 Ludian, 2016 Meinong, 2018 Hualien earthquakes. The amplitude of the ground vibrations at the B770 seismic station after the Meinong earthquake is shown in Figure S1. The enhancements of the ground vibrations at the example stations, the spatial distribution of the enhancements, and the determination of the source locations are shown in Figures S2-S4 for the Parkfield earthquake, Figures S5-S7 for the Baja earthquake, Figures S8-S10 for the Jinggu earthquake, Figures S11-S13 for the Ludian earthquake, and Figures S14-S16 for the Hualien earthquake. The amplitudes computed from the magnetic data could be dominated by the ground vibrations before the Meinong earthquakes are shown in Figures S17 and S18. The amplitudes computed from the magnetic data could be dominated by the ground vibrations before the Parkfield earthquakes are shown in Figure S19.

Author Contributions: Conceptualization, C.-H.C.; methodology, C.-H.C.; formal analysis, C.-H.C., L.-C.L., T.-K.Y., S.W., H.Y., C.Y., P.H.; resources, L.-C.L., T.-K.Y., H.Y., C.Y., Y.G., C.-C.T., L.-C.L., C.-M.L., H.-H.H., P.-J.L.; writing-original draft preparation, C.-H.C.; writing—review and editing, L.-C.L., S.W., Y.-Y.S., J.-Y.L., C.-H.L., P.-J.L.; visualization, C.-H.C. All authors have read and agreed to the published version of the manuscript.

Funding: This research was funded by National Key R\&D Program of China, grant number 2018YFC1503705 and 2018YFE0109700; National Natural Science Foundation of China, grant number 41474038 and 41774048 ; Spark Program of Earthquake Science of China, grant number xh17045; Ministry of Science and Technology of Taiwan, grant number MOST 106-2116-M-194-016- and MOST 106-2628-M-008-002; Sichuan earthquake Agency-Research 
Team of GNSS based geodetic tectonophysics and mantle-crust dynamics of Chuan-Dian region, grant number 201803. Meanwhile, this work was also supported by the Center for Astronautical Physics and Engineering (CAPE) from the Featured Area Research Center program within the framework of Higher Education Sprout Project by the Ministry of Education (MOE) in Taiwan.

Data Availability: Seismic, GNSS, and geomagnetic data for Taiwan. Seismic waveform data in Taiwan were provided by the Seismic Array of NCREE in Taiwan (SANTA), which is a multipurpose seismograph network operated by the National Center for Research on Earthquake Engineering (NCREE) since June 2012. SANTA includes thirty-seven seismograph stations uniformly distributed over the entire island of Taiwan. The broadband seismic waveforms recorded by a ground-velocity broadband seismometer (CMG-6TD, Guralp Systems Ltd.) were analyzed for the cases in Taiwan. The GNSS data in Taiwan were provided by the Geophysical Database Management System of the Central Weather Bureau [23]. A total of thirty-six GNSS stations were selected, and the Canadian Spatial Reference System (CSRS) Precise Point Positioning (PPP) online computation tool was utilized to calculate the 3D coordinates of the GNSS stations. The CSRS-PPP system uses the precise GNSS satellite orbit ephemerides; therefore, the coordinates in this study were taken from the International Terrestrial Reference Frame 2014. Moreover, the kinematic mode was adopted in the data processing and the coordinates were produced every $30 \mathrm{~s}$. To increase the accuracy of the data processing, an ocean tide loading correction was applied and the NAO.99b model was used to obtain the optimal correction effect [24]. Geomagnetic data associated with the Meinong earthquake were retrieved from the Institute of Earth Sciences, Academia Sinica, and the Central Weather Bureau, Taipei, Taiwan.

Acknowledgments: The authors appreciate scientists who devote to maintain instruments in the field and data centers in the office that leads chances to expose such interesting geophysical phenomena and understand potential processes during seismogenic periods.

Conflicts of Interest: The authors declare no conflict of interest.

\section{References}

1. Fraser-Smith, A.C.; Bernardi, A.; McGill, P.; Ladd, M.E.; Helliwell, R.; Villard, O.G., Jr. Low-frequency magnetic field measurements near the epicenter of the Ms 7.1 Loma Prieta earthquake. Geophys. Res. Lett. 1990, 17, 1465-1468. [CrossRef]

2. Campbell, W.H. Natural magnetic disturbance fields, not precursors preceding the Loma Prieta earthquake. J. Geophys. Res. 2009, 114, A05307. [CrossRef]

3. Uyeda, S.; Nagao, T.; Kamogawa, M. Short-term earthquake prediction: Current status of seismo-electromagnetics. Tectonophysics 2009, 470, 205-213. [CrossRef]

4. Kappler, K.N.; Morrison, H.F.; Egbert, G.D. Long-term monitoring of ULF electromagnetic fields at Parkfield, California. J. Geophys. Res. 2010, 115, B04406. [CrossRef]

5. Hattori, K.; Han, P.; Yoshino, C.; Febriani, F.; Yamaguchi, H.; Chen, C. Investigation of ULF seismo-magnetic phenomena in Kanto, Japan during 2000-2010: Case studies and statistical studies. Surv. Geophys. 2013, 34, 293-316. [CrossRef]

6. Wang, T.; Zhuang, J.; Kato, T.; Bebbington, M. Assessing the potential improvement in short-term earthquake forecasts from incorporation of GPS data. Geophys. Res. Lett. 2013, 40, 2631-2635. [CrossRef]

7. Han, P.; Hattori, K.; Hirokawa, M.; Zhuang, J.; Chen, C.; Febriani, F.; Yamaguchi, H.; Yoshino, C.; Liu, J.; Yoshida, S. Statistical analysis of ULF seismo-magnetic phenomena at Kakioka, Japan, during 2001-2010. J. Geophys. Res. Space Phys. 2014, 119, 4998-5011. [CrossRef]

8. Hayakawa, M.; Kasahara, Y.; Nakamura, T.; Muto, F.; Horie, T.; Maekawa, S.; Hobara, Y.; Rozhnoi, A.A.; Solovieva, M.; Molchanov, O.A. A statistical study on the correlation between lower ionospheric perturbations as seen by subionospheric VLF/LF propagation and earthquakes. J. Geophys. Res. 2010, 115, A09305. [CrossRef]

9. Sun, Y.Y.; Oyama, K.-I.; Liu, J.Y.; Jhuang, H.K.; Cheng, C.Z. The neutral temperature in the ionospheric dynamo region and the ionospheric F region density during Wenchuan and Pingtung Doublet earthquakes. Nat. Hazards Earth Syst. Sci. 2011, 11, 1759-1768. [CrossRef]

10. Klimenko, M.V.; Klimenko, V.V.; Karpov, I.V.; Zakharenkova, I.E. Simulation of seismo-ionospheric effects initiated by internal gravity waves. J. Phys. Chem. B 2011, 5, 393-401. [CrossRef]

11. Klimenko, M.V.; Klimenko, V.V.; Zakharenkova, I.E.; Karpov, I.V. Modeling of local disturbance formation in the ionosphere electron concentration before strong earthquakes. Earth Planets Space 2012, 64, 441-450. [CrossRef] 
12. Oyama, K.-I.; Devi, M.; Ryu, K.; Chen, C.-H.; Liu, J.-Y.; Liu, H.; Bankov, L.; Kodama, T. Modifications of the ionosphere prior to large earthquakes: Report from the Ionosphere Precursor Study Group. Geosci. Lett. 2016, 3, 6. [CrossRef]

13. Bedford, J.R.; Moreno, M.; Deng, Z.; Oncken, O.; Schurr, B.; John, T.; Báez, J.C.; Bevis, M. Months-long thousand-kilometre-scale wobbling before great subduction earthquakes. Nature 2020, 580, 628-635. [CrossRef] [PubMed]

14. Chen, C.H.; Yeh, T.K.; Liu, J.Y.; Wang, C.H.; Wen, S.; Yen, H.Y.; Chang, S.H. Surface Deformation and Seismic Rebound: Implications and applications. Surv. Geophys. 2011, 32, 291-313. [CrossRef]

15. Chen, C.H.; Tang, C.C.; Cheng, K.C.; Wang, C.H.; Wen, S.; Lin, C.H.; Wen, Y.Y.; Meng, G.; Yeh, T.K.; Jan, J.C.; et al. Groundwater-strain coupling before the 1999 Mw 7.6 Taiwan Chi-Chi earthquake. J. Hydrol. 2015, 524, 378-384. [CrossRef]

16. Chen, C.H.; Yeh, T.K.; Wen, S.; Meng, G.; Han, P.; Tang, C.C.; Liu, J.Y.; Wang, C.H. Unique Pre-Earthquake Deformation Patterns in the Spatial Domains from GPS in Taiwan. Remote Sens. 2020, 12, 366. [CrossRef]

17. Chen, C.H.; Su, X.; Cheng, K.C.; Meng, G.; Wen, S.; Han, P.; Tang, C.C.; Liu, J.Y.; Wang, C.H. Seismo-deformation anomalies associated with the M6.1 Ludian earthquake on August 3, 2014. Remote Sens. 2020, 12, 1067. [CrossRef]

18. Mao, Z.; Chen, C.-H.; Zhang, S.; Yisimayili, A.; Yu, H.; Yu, C.; Liu, J.-Y. Locating Seismo-Conductivity Anomaly before the $2017 \mathrm{M}_{\mathrm{W}} 6.5$ Jiuzhaigou Earthquake in China Using Far Magnetic Stations. Remote Sens. 2020, 12, 1777. [CrossRef]

19. Dragert, H.; Wang, K.; James, T.S. A Silent Slip Event on the Deeper Cascadia Subduction Interface. Science 2001, 292, 1525-1528. [CrossRef]

20. Obara, K. Nonvolcanic Deep Tremor Associated with Subduction in south west Japan. Science 2002, 296, 1679-1681. [CrossRef]

21. Kostoglodov, V.; Singh, S.K.; Santiago, J.A.; Franco, S.I.; Larson, K.M.; Lowry, A.R.; Bilham, R. A large silent earthquake in the Guerrero seismic gap, Mexico. Geophys. Res. Lett. 2003, 30, 157-168. [CrossRef]

22. Rogers, G.; Dragert, H. Episodic Tremor and slip on the Cascadia Subduction Zone: The chatter of silent slip. Science 2003, 300, 1942-1943. [CrossRef] [PubMed]

23. Shin, T.C.; Kuo, K.W.; Leu, P.L.; Tsai, C.H.; Jiang, J.S. Continuous CWB GPS array in Taiwan and applications to monitoring seismic activity. Terr. Atmos. Ocean. Sci. 2011, 22, 521-533. [CrossRef]

24. Chung, Y.D.; Yeh, T.K.; Xu, G.; Chen, C.S.; Hwang, C.; Shih, H.C. GPS height variations affected by ocean tidal loading along the coast of Taiwan. IEEE Sens. J. 2016, 16, 3697-3704. [CrossRef]

25. Yeh, T.-K.; Huang, C.; Xu, G. GPS height and gravity variations due to ocean tidal loading around Taiwan. Surv. Geophys. 2008, 29,37-50. [CrossRef]

26. Yeh, T.-K.; Hwang, C.-H.; Huang, J.-F.; Chao, B.F.; Chang, M.-H. Vertical displacement due to ocean tidal loading around Taiwan based on GPS observations. Terr. Atmos. Ocean. Sci. 2011, 22, 373-382. [CrossRef]

27. Tanimoto, T.; Ishimaru, S.; Alvizuri1, C. Seasonality in particle motion of microseisms. Geophys. J. Int. 2006, 166, 253-266. [CrossRef]

28. Jolliffe, I.T. Principal Component Analysis; Springer: New York, NY, USA, 2002; ISBN 978-0-387-95442-4.

29. Phanikumar, D.V.; Maurya, A.K.; Kumar, K.N.; Venkatesham, K.; Singh, R.; Sharma, S.; Naja, M. Anomalous variations of VLF subionospheric signal and Mesospheric Ozone prior to 2015 Gorkha Nepal Earthquake. Sci. Rep. 2018, 8, 9381. [CrossRef]

30. Molchan, G.M. Structure of optimal strategies in earthquake prediction. Tectonophysics 1991, 193, $267-276$. [CrossRef]

31. Dobrovolsky, I.P.; Zubkov, S.I.; Miachkin, V.I. Estimation of the size of earthquake preparation zones. Pure Appl. Geophys. 1979, 117, 1025-1044. [CrossRef]

32. Chen, C.H.; Wen, S.; Liu, J.Y.; Hattori, K.; Han, P.; Hobara, Y.; Wang, C.H.; Yeh, T.K.; Yen, H.Y. Surface displacements in Japan before the 11 March 2011 M9.0 Tohoku-Oki earthquake. J. Asian Earth Sci. 2014, 80, 165-171. [CrossRef]

33. Walczak, P.; Mezzapesa, F.; Bouakline, A.; Ambre, J.; Bouissou, S.; Barland, B. Real time observation of granular rock analogue material deformation and failure using nonlinear laser interferometry. arXiv preprint 2017, arXiv:1705.03377v1.

34. Leissa, A.W. Vibrations of Plates; Ohio State University: Columbus, OH, USA, 1969. 
35. Vilarrasa, V.; Carrera, J. Geologic carbon storage is unlikely to trigger large earthquakes and reactivate faults through which $\mathrm{CO}_{2}$ could leak. Proc. Natl. Acad. Sci. USA 2015, 112, 5938-5943. [CrossRef] [PubMed]

36. Liu, J.Y.; Chen, Y.I.; Chen, C.H.; Liu, C.Y.; Chen, C.Y.; Nishihashi, M.; Li, J.Z.; Xia, Y.Q.; Oyama, K.I.; Hattori, K.; et al. Seismoionospheric GPS total electron content anomalies observed before the 12 May 2008 Mw 7.9 Wenchuan earthquake. J. Geophys. Res. 2009, 114, A04320. [CrossRef]

37. Liu, J.Y.; Chen, C.H.; Sun, Y.Y.; Chen, C.H.; Tsai, H.F.; Yen, H.Y.; Chum, J.; Lastovicka, J.; Yang, Q.S.; Chen, W.S.; et al. The vertical propagation of disturbances triggered by seismic waves of the 11 March 2011 M9.0 Tohoku Earthquake over Taiwan. Geophys. Res. Lett. 2016, 43, 1759-1765. [CrossRef]

(C) 2020 by the authors. Licensee MDPI, Basel, Switzerland. This article is an open access article distributed under the terms and conditions of the Creative Commons Attribution (CC BY) license (http://creativecommons.org/licenses/by/4.0/). 